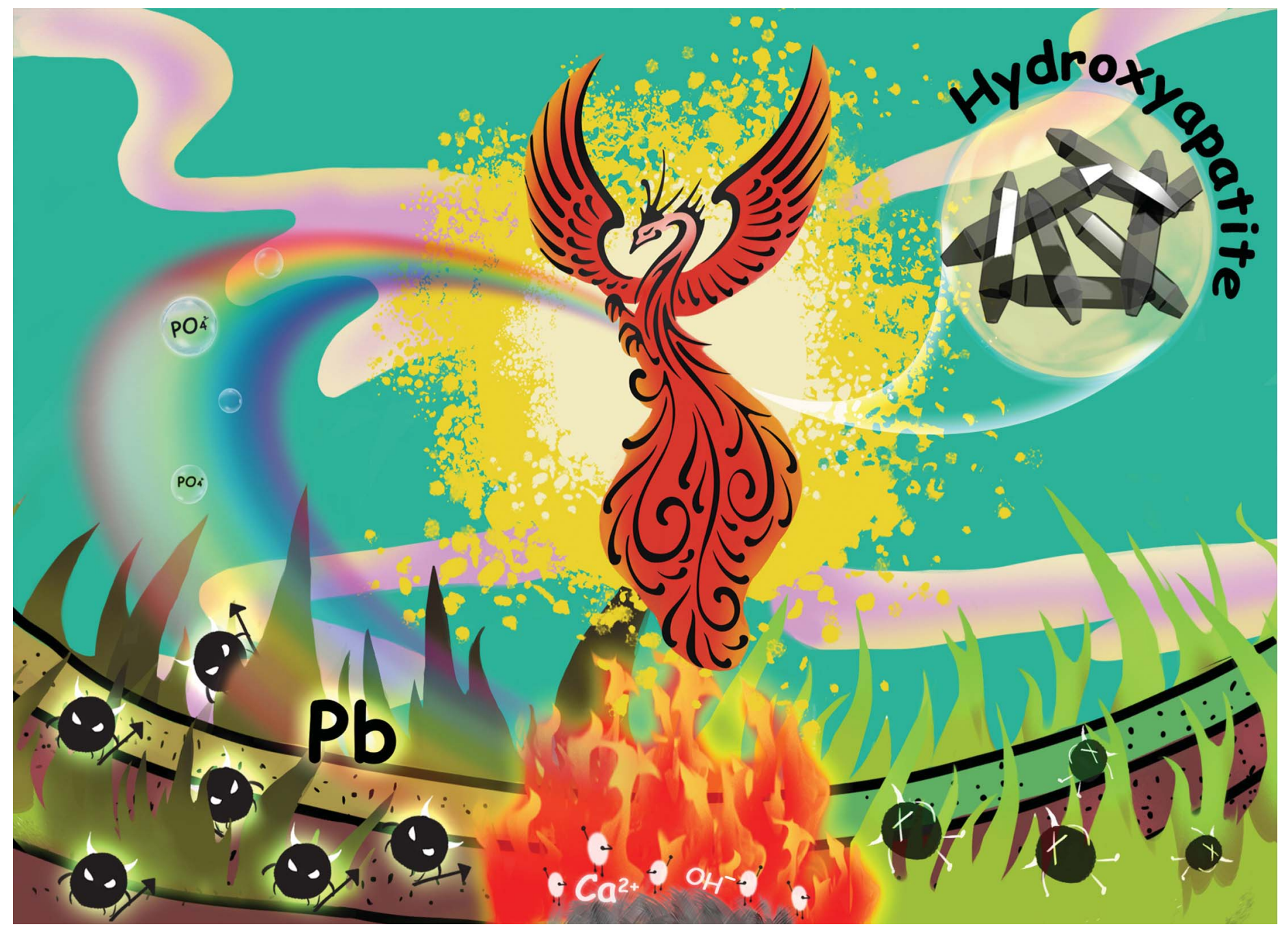

Showcasing research from Prof. Aiguo Wu's group at Ningbo Institute of Materials Technology and Engineering, Chinese Academy of Sciences, Ningbo, China

Suppression of the environmental risks of lead in cropland soil using biomass ash and its modified product

Biomass ash (BA) was used as a low-cost raw material for the preparation of soil amendment to suppress the environmental risks of lead in cropland soil. BA was successfully modified via a hydrothermal technique and the modified ash (MA) showed less interference to soil $\mathrm{pH}$, higher immobilization efficiency, and better immobilization stability to lead in soil than BA.

\section{As featured in:}

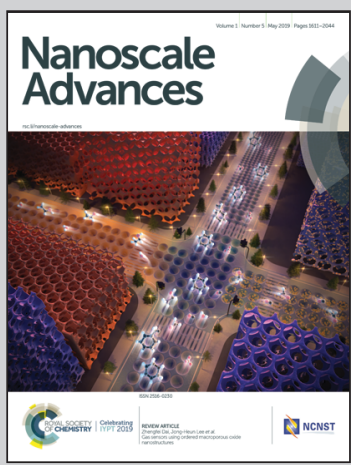

See Yujie Zhang, Aiguo Wu et al., Nanoscale Adv., 2019, 1, 1740. 
Check for updates

Cite this: Nanoscale Adv., 2019, 1, 1740

\title{
Suppression of the environmental risks of lead in cropland soil using biomass ash and its modified product $\uparrow$
}

\author{
Hongyu Liu, ${ }^{\text {ab }}$ Zhuangwei Zhou, ${ }^{a}$ Yujie Zhang, ${ }^{\text {a }}$ Ningyi Chen, ${ }^{\text {ab }}$ Jingyan Kang, ${ }^{a}$

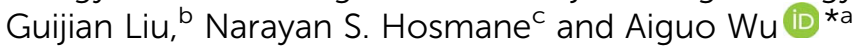

In this work, modified biomass ash (MA), obtained through the hydrothermal treatment technique with biomass ash (BA) and alkaline phosphate as raw materials, was used as a useful soil amendment to reduce the environmental risk of lead and was compared with raw ash. In order to confirm the composition changes from BA to MA, the materials before and after modification were characterized by using transmission electron microscopy (TEM), energy dispersive spectroscopy (EDS), Fourier transform infrared (FT-IR) spectroscopy, and X-ray diffraction (XRD). Subsequently, the suppression of the environmental risks of lead in the contaminated cropland soil by MA and BA was systematically investigated through $\mathrm{pH}$ evaluation, toxicity-extraction, and fractional analysis. The results show that needle-like hydroxyapatite nanoparticles were generated during the modification process of BA. After incubation with 5\% BA and 5\% MA for 60 days, the pH of soil samples increased from 5.46 to 7.20 and 6.83, respectively; the lead concentration by TCLP extraction decreased by about $52.6 \%$ and $95.2 \%$, respectively. And the content of lead bound to RES increased from $36.28 \%$ to $49.09 \%$ and $59.58 \%$, respectively. MA showed higher immobilization efficiency, better immobilization stability, and less disturbance to the soil $\mathrm{pH}$ than $\mathrm{BA}$, and it can suppress the environmental risk of lead below the standard toxicity level. These results undoubtedly demonstrate that BA has great potential in the practical application of remediation of lead contaminated soil, and its modified product may become a useful amendment to suppress and/or eliminate the high environmental risk of lead by transforming industrial waste into useful nanomaterials for green environmental chemistry.

Received 1st January 2019
Accepted 8th April 2019
DOI: 10.1039/c9na00001a
rsc.li/nanoscale-advances

\section{Introduction}

Lead $(\mathrm{Pb})$ is a heavy metal element with potent neurotoxicity and even low levels of exposure can have a profound and longlasting effect on human health. The Centers for Disease Control and Prevention defines that the blood lead level (BLL) is $5 \mu \mathrm{g}$ $\mathrm{dL}^{-1}$ in order to protect human health, particularly for the safety of children. ${ }^{1}$ In previous research, the results showed that bioavailable lead concentration in soil is positively correlated with human BLL. ${ }^{2}$ It is urgent to suppress and/or eliminate the environmental risk of lead in contaminated soils, such as in farmland, post-industrial environments or urban soils. For

\footnotetext{
${ }^{a}$ Cixi Institute of Biomedical Engineering, CAS Key Laboratory of Magnetic Materials and Devices \& Key Laboratory of Additive Manufacturing Materials of Zhejiang Province, Ningbo Institute of Materials Technology and Engineering, Chinese Academy of Sciences, Ningbo 315201, China. E-mail: aiguo@nimte.ac.cn; zhangyujie@nimte.ac.cn; Fax: +86 574 86685163; Tel: +8657486685039

${ }^{b}$ University of Science and Technology of China, Hefei 230026, China

'Department of Chemistry and Biochemistry, Northern Illinois University, DeKalb, IL 60115, USA

$\uparrow$ Electronic supplementary information (ESI) available. See DOI: 10.1039/c9na00001a
}

these soils, the major pathways for exposure of humans to lead include consumption of contaminated food and inhalation of soil particles. ${ }^{3}$ The most widely used way to suppress the environmental risk of lead in soils is in situ remediation by utilizing the chemical immobilization method, in which the new materials added into soil (soil amendments) can transform heavy metals from the available state to a stable fixed state. ${ }^{4-6}$ Consequently, this transformation decreases the mobility and bioavailability of toxic heavy metals with available state and high concentration. Nonetheless, the current protocols for in situ remediation are severely restricted by the large area of soil, large demand and high price of amendments. ${ }^{7-9}$

Biomass resources are extremely abundant in agricultural producing countries like China, India, Bangladesh, Brazil, US, Cambodia, Vietnam, Myanmar, and Southeast Asia. ${ }^{10}$ Biomass has been widely used for energy production all over the world and is considered as an environmentally safe way for energy access; during the process a solid by-product is produced, namely biomass ash (BA). ${ }^{11-13}$ The utilization of biomass ash has become an important issue for the sustainable development of biomass energy. ${ }^{14}$ Biomass ash is low cost and environmentally friendly, and is often used to improve the soil fertility during 
agricultural production. It also has good functional application in the adsorption of pollutants in water. ${ }^{15,16}$ In this work, the biomass ash from burning wheat stem, maize straw, groundnut shell, cotton stalk and other agricultural residues was modified and used as a new passivation material for lead contaminated soil, which can provide scientific guidance for the selection of soil amendments. The results of this investigation are presented in detail.

\section{Materials and methods}

\subsection{Materials}

Biomass ash was obtained from Anhui Guozhen Biomass Power Co., Ltd., China. Modified biomass ash (MA) was prepared by using a hydrothermal reaction with biomass ash and alkaline phosphate as raw materials. In order to simulate natural mineralization, the specific preparation process was as follows: first, the total content of Ca in BA was measured by using X-Ray Fluorescence spectra (XRF) analysis (S1 in the ESI $\dagger$ ). Subsequently, $5 \mathrm{~g}$ biomass ash and a calculated amount of disodium hydrogen phosphate were dispersed into $40 \mathrm{~mL}$ Milli-Q water to ensure that the molar ratio of $\mathrm{Ca} / \mathrm{P}$ in the mixed solution was 1.67. The mixture was stirred evenly, stored for $1 \mathrm{~h}$, and then poured into a $50 \mathrm{~mL}$ hydrothermal reactor. The sealed reactor was heated to $200{ }^{\circ} \mathrm{C}$ in an air drying oven and maintained for $20 \mathrm{~h}$. Finally, the solid residues were filtered, washed by using Milli-Q water and dried to a constant weight at $40-60{ }^{\circ} \mathrm{C}$. The liquid wastes were collected for soluble by-product analyses.

\subsection{Characterization of BA and MA}

To determine the morphology and structure of BA and MA, transmission electron microscope (TEM) images were recorded on a JEOL 2100 instrument (JEOL, Japan). The corresponding energy dispersive spectroscopy (EDS) data were obtained to identify the elemental composition of BA and MA. Fouriertransform infrared (FT-IR) spectra measurements were carried out on a NICOLET 6700 (Thermo Corporation, USA) in the range of 400 to $4000 \mathrm{~cm}^{-1}$ by the $\mathrm{KBr}$ method. The crystal type, phase and pattern of BA and MA were determined by the X-ray diffraction (XRD, D8 Advance, Bruker AXS, Germany) method over an angular range of $15-90^{\circ} 2 \theta$ with $\mathrm{Cu} \mathrm{K} \alpha$ radiation $(40 \mathrm{kV}$, $40 \mathrm{~mA})$.

\subsection{Soils}

Lead contaminated soil was collected at a depth of $0-20 \mathrm{~cm}$ of cropland soil in a red sandstone area. ${ }^{17}$ All sample digging areas have been polluted for many years by surrounding chemical enterprises. The soil samples were collected with an equal amount at random excavation points and well-mixed. The original soil samples were air-dried at room temperature for 5 days, ground, and sieved with a $2 \mathrm{~mm}$ mesh. The soil samples were analyzed to obtain the $\mathrm{pH}$ value, organic matter (OM), cation exchange capacity (CEC), available phosphorus (P), potassium $(\mathrm{K})$, and nitrogen $(\mathrm{N})$, along with the total content of $\mathrm{Pb}$ (S1 in the ESI $\dagger$ ). The ecological toxicity of lead in soil was evaluated by the toxicity characteristic leaching procedure (TCLP) before incubation experiments.

\subsection{Incubation procedure}

$100 \mathrm{~g}$ original soil sample was mixed with BA and MA with a weight rate of $2.5 \%$ and $5.0 \%$ in a $200 \mathrm{~mL}$ plastic beaker, respectively. A soil sample without BA or MA (0.0\%) was used as the control. Each treatment had three replicates, with a total of 15 samples. All plastic beakers were incubated under greenhouse conditions for 60 days within the temperature range of 18-25 ${ }^{\circ} \mathrm{C}$ and with a moisture content of $15 \pm 5 \%$ by the weighing method. Milli-Q water was used in order to maintain the water holding capacity of soil during the incubation period. The soil samples were collected at 7, 15, 30, and 60 days for $\mathrm{pH}$ analysis and lead toxicity measurements by the TCLP method. After 60 days, the classification of lead in soil was determined by the Tessier sequential extraction procedure.

\subsection{TCLP extraction of the soil sample}

The TCLP method is widely used to evaluate the mobility, bioavailability and toxicity of heavy metals in soil and waste. ${ }^{5,18-20}$ Depending on the $\mathrm{pH}$ value of the soil sample, TCLP extraction was performed as follows. $5.7 \mathrm{~mL}$ glacial acetic acid was diluted to 1 liter with Milli-Q water. The $\mathrm{pH}$ of the solution was adjusted to $2.88 \pm 0.05$ by using $\mathrm{NaOH}$ and the final solution was used as an extraction solution of the TCLP method. Subsequently, $2 \mathrm{~g}$ soil sample was dispersed into $40 \mathrm{~mL}$ of the above extraction solution, shaken and mixed. After equilibration, the $\mathrm{Pb}$ concentration in the filtrate was measured by using inductively coupled plasma optical emission spectroscopy (ICPOES).

\subsection{Sequential extraction of the soil sample}

The Tessier sequential extraction method is widely used to determine the form change of metals during in situ remediation. ${ }^{21}$ In this work, the Tessier sequential extraction procedure was used to evaluate the change of lead speciation and solidphase association of lead in soil to divide the lead speciation in the soil sample into five fractions with three replicates: (1) exchangeable (EXC), (2) carbonates (CA), (3) Fe-Mn oxides (Fe$\mathrm{Mn}$ ), (4) organic matter (OM), and (5) residue (RES). The $\mathrm{Pb}$ content in each speciation was determined by using ICP-OES. In order to ensure the accuracy of analysis results, a certified soil reference material (GBW07445, National Research Center for Certified Reference Materials, China) was used.

\subsection{Data analyses}

For each incubation treatment, the mean $\mathrm{pH}$ value and lead content in each speciation were compared by using one-way analysis of variance (ANOVA). Statistically significant differences were determined by the Fisher least significant difference (LSD) test $(P<0.05)$. 


\section{Results and discussion}

\subsection{Characterization of BA and MA}

The morphology and composition of BA and MA were characterized by TEM and corresponding EDS analysis. As shown in Fig. 1a, the morphology of BA is irregular, with a significant amount of nanoparticles bonded together. The corresponding EDS spectrum shows that BA contains a lot of conventional elements, such as $\mathrm{Ca}, \mathrm{Si}, \mathrm{O}, \mathrm{Fe}, \mathrm{K}, \mathrm{Al}, \mathrm{Mg}, \mathrm{Cl}, \mathrm{P}, \mathrm{S}, \mathrm{Na}, \mathrm{Mn}$, and other trace elements. It is noticeable that the above elements are nutritional substances of soils and necessary minerals for plants and crops. The relative content of various elements in BA is given in the ESI (Table S2 $\dagger$ ). The EDS spectrum of BA shows that the relative content of $\mathrm{Ca}$ in $\mathrm{BA}$ is the highest. As a result, BA can provide enough Ca source for the hydrothermal reaction during the modification procedure. As reported by Steenari et al., the contents of $\mathrm{Ca}, \mathrm{K}, \mathrm{Na}, \mathrm{Mg}$ and other salts in the ash of biofuel are so high with obvious alkaline characteristics. ${ }^{22}$ Similarly, BA used in this study is composed of numerous alkali metals and alkaline-earth metals, such as $\mathrm{Ca}, \mathrm{K}, \mathrm{Na}$, and $\mathrm{Mg}$ with high alkalinity (Tables S1 and $\mathrm{S} 2 \dagger$ ), which can supply an alkaline environment for the hydrothermal reaction. In comparison with BA, MA exhibits a needle-like nanocrystalline structure, consisting of $\mathrm{Ca}, \mathrm{P}$, and $\mathrm{O}$ elements (Fig. 1b). The relative content of $\mathrm{P}$ increased significantly in MA compared with that in BA (Table $\mathrm{S} 2 \dagger$ ). These results unambiguously confirm the presence of insoluble phosphates in MA.

The main compositions of crystal substances in BA and MA were examined by XRD analysis. As shown in Fig. 2a, BA mainly consists of quartz $\left(\mathrm{SiO}_{2}\right)$ and calcite $\left(\mathrm{CaCO}_{3}\right)$. However, the diffraction peaks of calcite in MA (Fig. 2b) weaken obviously and nearly disappear, and the diffraction peaks of hydroxyapatite $\left(\mathrm{HA}, \mathrm{Ca}_{10}\left(\mathrm{PO}_{4}\right)_{6}(\mathrm{OH})_{2}\right)$ appear in the XRD pattern of MA. These
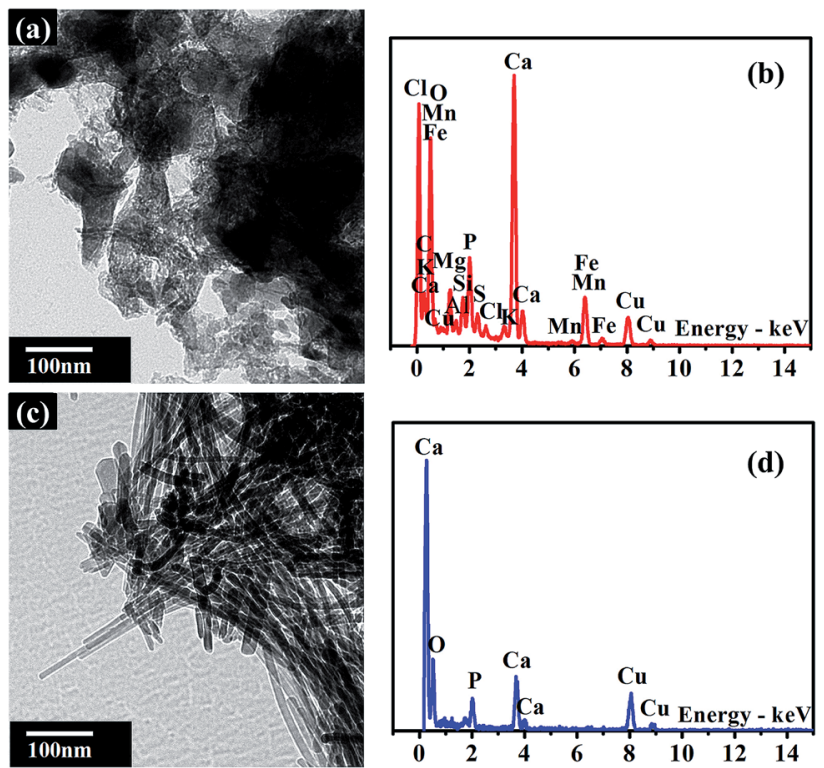

Fig. 1 TEM images and corresponding EDS spectra of BA ( $a$ and $b$ ) and MA (c and d) samples.

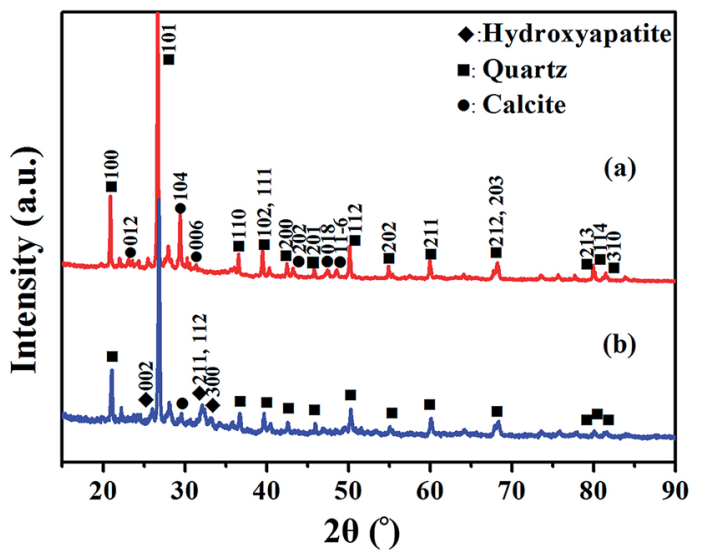

Fig. 2 XRD patterns of BA (a) and MA (b) samples.

results indicate that needlelike HA nanoparticles are generated during the modification process of $\mathrm{BA}$, in which $\mathrm{Ca}^{2+}$ and $\mathrm{OH}^{-}$ are supplied by calcite and alkaline substances in BA. As shown in Fig. $\mathrm{S} 1, \dagger$ the soluble by-products during the modification process include sodium bicarbonate $\left(\mathrm{NaHCO}_{3}\right)$ and sodium carbonate $\left(\mathrm{Na}_{2} \mathrm{CO}_{3}\right)$. Therefore, all the above results indicate that the nanoscale hydroxyapatite should be formed according to the following reaction equation:

$$
\begin{gathered}
10 \mathrm{CaCO}_{3}+6 \mathrm{Na}_{2} \mathrm{HPO}_{4}+2 \mathrm{H}_{2} \mathrm{O} \rightarrow \mathrm{Ca}_{10}\left(\mathrm{PO}_{4}\right)_{6}(\mathrm{OH})_{2}+ \\
8 \mathrm{NaHCO}_{3}+2 \mathrm{Na}_{2} \mathrm{CO}_{3}
\end{gathered}
$$

The FT-IR spectra of BA and MA are shown in Fig. 3. Accordingly, both BA and MA show strong absorption peaks at 1039-1034, 777-781, 686-690 and 457-463 $\mathrm{cm}^{-1}$, corresponding to the $\mathrm{Si}-\mathrm{O}-\mathrm{Si}$ asymmetric stretching vibration, $\mathrm{Si}-\mathrm{O}-\mathrm{Si}$ symmetric stretching vibration, $\mathrm{Si}-\mathrm{O}$ in-plane bending vibration and $\mathrm{Si}-\mathrm{O}$ out-of-plane bending vibration of $\mathrm{SiO}_{2}$, respectively. In addition, the presence of $\mathrm{CO}_{3}{ }^{2-}$ ions in BA can be deduced from the peaks at 1421, 875 and $715 \mathrm{~cm}^{-1}$, which is consistent with the presence of calcite in BA. In the FT-IR spectrum of MA, the

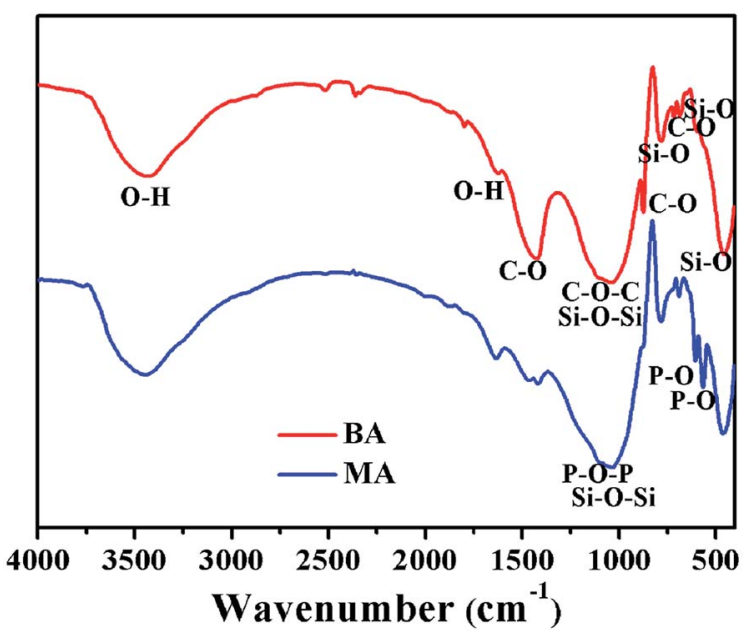

Fig. 3 FT-IR spectra of BA and MA. 
peaks at 606 and $567 \mathrm{~cm}^{-1}$ indicate the presence of $\mathrm{PO}_{4}{ }^{3-}$ ions in MA. IR spectroscopic data of MA further prove that HA is generated during the modification process of BA.

\subsection{Effect of the amendment on the $\mathrm{pH}$ value of soil}

The $\mathrm{pH}$ value is an important parameter of soil properties, which can affect the immobilization and dissolution of heavy metals in soils. ${ }^{23}$ The $\mathrm{pH}$ variation of the soil samples was measured after incubation with BA and MA for 7, 15, 30 and 60 days, respectively. As shown in Fig. 4, both BA and MA increase $(P<0.05)$ the $\mathrm{pH}$ value of the soil significantly compared with the untreated soil (CK) during the incubation period. After incubation for 60 days, as for the $\mathrm{CK}$ sample, the $\mathrm{pH}$ values of the soil samples incubated with $2.5 \%$ BA and MA are increased to 7.05 and 6.59 , and the $\mathrm{pH}$ values are increased to 7.20 and 6.83 with 5\% BA and MA. For the same amendment, with the increase of the adding amount, there is a slight increase in the soil $\mathrm{pH}$.

For BA, the increase of soil $\mathrm{pH}$ can be explained by the dissolution of alkali salts in acid soil solution. For MA, the $\mathrm{pH}$ increase of soil can be due to (1) the effects of alkali salts that remained in MA and (2) the dissolution of HA and/or isomorphous substitution in the soil solution $\left(\mathrm{OH}^{-}\right.$in $\mathrm{HA}$ is substituted by anions in soil solution, like $\mathrm{F}^{-}, \mathrm{Cl}^{-}$, and so on). ${ }^{24,25}$

Normally, the solubility and toxicity of heavy metals decrease with the increase of soil $\mathrm{pH}$. However, large changes in soil $\mathrm{pH}$ should be avoided to make the soil a safe and green environment. During long-term incubation, MA shows a smaller influence and/or disturbance on/to the soil pH than BA with the same adding amount. The possible reasons are as follows: (1) the alkaline character of MA is "immobilized" in HA; (2) the solubility of HA is very low, ${ }^{26}$ and (3) the process of isomorphous substitution for $\mathrm{OH}^{-}$in soil solution is slow and incomplete, which mainly occurs on the surface of HA particles.

\subsection{TCLP extraction of soil samples}

The immobilization efficiency of the amendments for lead in the soil was evaluated by the TCLP extraction test. As shown in Table 1 and Fig. 5, the untreated soil samples are highly contaminated by toxic lead, in which the $\mathrm{Pb}^{2+}$ concentration is drastically higher than the toxicity level specified by the US EPA (Pb: $\left.5 \mathrm{mg} \mathrm{L}{ }^{-1}\right){ }^{20,27}$ After incubation with BA and MA (2.5\% and $5 \%$ by weight), the content of bioavailable lead reduces
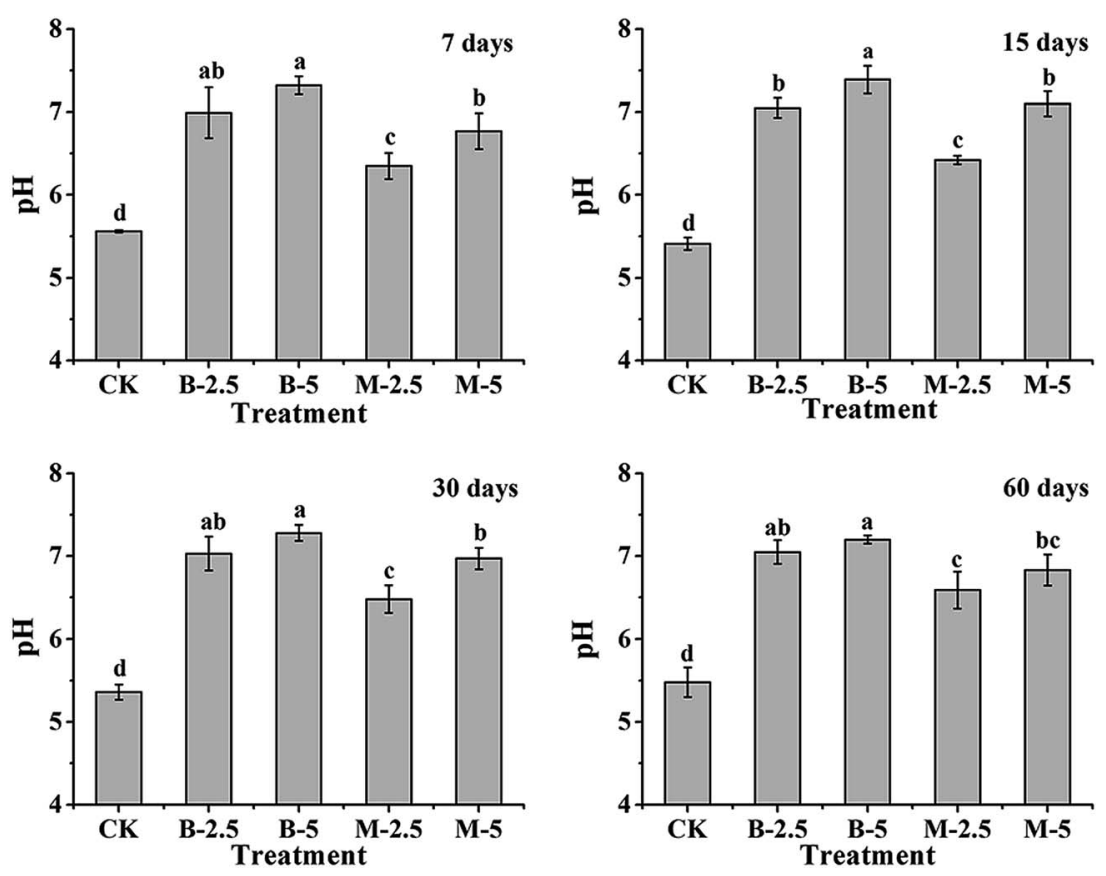

Fig. 4 The influence of $\mathrm{BA}$ and $\mathrm{MA}$ on the soil $\mathrm{pH}$ by incubation for $7,15,30$ and 60 days (CK $=$ untreated soil, $\mathrm{B}-2.5=2.5 \% \mathrm{BA}$ plus soil, $\mathrm{B}-5=5 \%$ BA plus soil, $M-2.5=2.5 \%$ MA plus soil, and $M-5=5 \%$ MA plus soil). For each remediation treatment, mean values with different letters indicate statistically significant differences according to the LSD test $(P<0.05)$.

Table 1 Basic physical and chemical properties of the tested soil

\begin{tabular}{|c|c|c|c|c|c|c|c|}
\hline $\mathrm{pH}$ & $\mathrm{OM}^{a} \mathrm{~g} \mathrm{~kg}^{-1}$ & $\mathrm{CEC}^{b} \mathrm{cmol} \mathrm{kg}^{-1}$ & $\begin{array}{l}\text { Available P mg } \\
\mathrm{kg}^{-1}\end{array}$ & $\begin{array}{l}\text { Available } \mathrm{K} \mathrm{mg} \\
\mathrm{kg}^{-1}\end{array}$ & $\begin{array}{l}\text { Available } \mathrm{N} \mathrm{mg} \\
\mathrm{kg}^{-1}\end{array}$ & $\begin{array}{l}\text { Total } \mathrm{Pb} \mathrm{mg} \\
\mathrm{kg}^{-1}\end{array}$ & $\operatorname{TCLP}^{c} \mathrm{~Pb} \mathrm{mg} \mathrm{kg}{ }^{-1}$ \\
\hline 5.46 & 26.0 & 3.30 & 132 & 104 & 91.0 & 89.7 & 17.5 \\
\hline
\end{tabular}

${ }^{a} \mathrm{OM}$, organic matter. ${ }^{b} \mathrm{CEC}$, cation exchange capacity. ${ }^{c}$ TCLP, toxicity characteristic leaching procedure. 


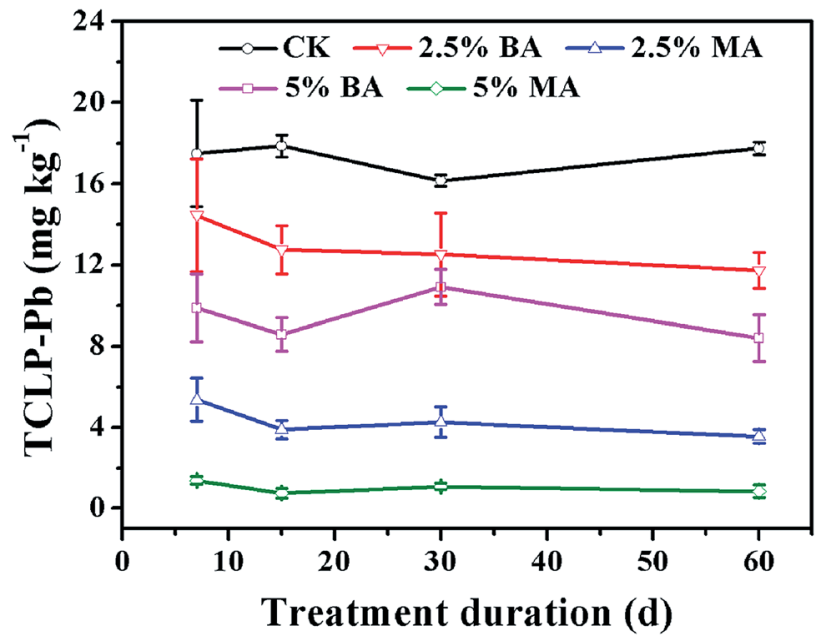

Fig. 5 Concentrations of lead by TCLP extraction from the $\mathrm{CK}$ and soils treated with BA and MA after long-term incubation.

significantly and the degree of reduction increases with the increase of time and the dosage of amendments. After incubation with $2.5 \%$ and $5 \%$ BA for 60 days, toxic lead contents are reduced by about $33.9 \%$ and $52.6 \%$, respectively; about $79.9 \%$ and $95.2 \%$ for MA-treated soil samples. It is obvious that MA can immobilize lead more effectively than BA even with low dosage. Moreover, it should be noted that the $\mathrm{Pb}^{2+}$ concentration by TCLP extraction is lower than the toxicity level specified by the US EPA when MA is used as a soil amendment.

The increase of soil $\mathrm{pH}$ is beneficial to the immobilization of available lead in soil due to precipitation. However, although the increase of the soil $\mathrm{pH}$ value by MA is lower than that by BA (Fig. 4), MA can immobilize the bioavailable lead more effectively than BA, which can be seen from Fig. 5 . The excellent lead immobilization efficiency of MA can be owing to the existence of nanoscale HA, which is well-known for its favorable lead adsorption and immobilization ability based on cation exchange and surface metal complexation reactions. ${ }^{3,5,28,29,30}$

\subsection{Fraction distribution of lead}

To determine the speciation change of lead and immobility performance of BA and MA, Tessier sequential extraction was performed after incubation for 60 days. It can be seen from Table 2 that after incubation with $2.5 \%$ and $5 \%$ BA for 60 days, the exchangeable lead concentrations decrease obviously from
$11.92 \%$ to $0.51 \%$ and $0.48 \%$, respectively, which are primarily transformed to $\mathrm{CA}, \mathrm{Fe}-\mathrm{Mn}$, and RES. With the increase of the adding amount of BA, more exchangeable lead is transformed to more stable speciation. The speciation change of lead after BA treatment can be explained by three reasons. First, $\mathrm{Ca}^{2+}$ in $\mathrm{CaCO}_{3}$ can be replaced by $\mathrm{Pb}^{2+}$ in soil solution due to the lower solubility product of $\mathrm{PbCO}_{3}$, which induces the increase of lead bound to the carbonate fraction. Second, the increase of soil $\mathrm{pH}$ by BA can lead to the formation of lead hydroxide, which induces the increase of lead bound to the Fe-Mn oxide fraction. Third, the increase of soil $\mathrm{pH}$ may cause the formation of some crystal minerals, which can transform lead into RES from other fractions.

Compared with BA, MA reduces both the exchangeable lead concentration and the concentration of lead bound to the carbonate fraction effectively (Table 2). After incubation with $2.5 \%$ and $5 \%$ MA, the exchangeable lead concentrations decrease from $11.92 \%$ to $3.38 \%$ and $1.52 \%$, respectively. The lead concentrations of $\mathrm{CA}$ are significantly decreased from $17.27 \%$ to $11.63 \%$ and $8.83 \%$, respectively. In addition, the lead contents bound to EXC and CA are significantly reduced with the increase of the adding amount of MA. Moreover, it should be noted that the concentration of lead bound to RES in the soil treated with MA increases more than that in the soil treated with BA. It is known that the exchangeable heavy metal is considered as easily mobile and bioavailable one. ${ }^{21}$ Heavy metals bound to $\mathrm{CA}, \mathrm{Fe}-\mathrm{Mn}$, and $\mathrm{OM}$ fractions are potentially bioavailable. The RES is the most stable among all five fractions and it is hard to be influenced by other conditions. The above results indicate that MA can promote the transformation of lead into a stable form more effectively than BA. Therefore, the durability of lead fixation by MA is stronger than that by BA due to the lower solubility of lead mineral species formed during the incubation than that of lead carbonate, lead hydroxide and so on.

\section{Conclusions}

In this study, a kind of true industrial waste (BA) was used as a low-cost raw material for the preparation of an amendment to reduce the environmental risk of lead in soil. According to the basic component and properties of BA, the ash was successfully modified through a hydrothermal reaction, in which Ca sources and the alkaline character of the ash play important roles in the formation of hydroxyapatite. After incubation with $5 \%$ BA and

Table 2 Percentage of lead in different speciation in soils incubated with BA and MA for 60 days ${ }^{a}$

\begin{tabular}{|c|c|c|c|c|c|}
\hline Treatment & EXC & $\mathrm{CA}$ & $\mathrm{Fe}-\mathrm{Mn}$ & OM & RES \\
\hline CK & $11.92 \pm 0.33 a$ & $17.27 \pm 0.14 b$ & $23.52 \pm 0.44 \mathrm{~b}$ & $11.00 \pm 0.11 \mathrm{a}$ & $36.28 \pm 0.16 \mathrm{~d}$ \\
\hline $2.5 \% \mathrm{BA}$ & $0.51 \pm 0.03 \mathrm{~d}$ & $22.44 \pm 1.85 a$ & $30.51 \pm 1.72 \mathrm{a}$ & $8.94 \pm 0.71 b$ & $37.60 \pm 0.90 \mathrm{~d}$ \\
\hline $5 \%$ BA & $0.48 \pm 0.03 \mathrm{~d}$ & $17.73 \pm 0.32 b$ & $23.42 \pm 1.11 b$ & $9.28 \pm 0.64 \mathrm{~b}$ & $49.09 \pm 1.52 b$ \\
\hline $2.5 \% \mathrm{MA}$ & $3.38 \pm 0.20 \mathrm{~b}$ & $11.63 \pm 0.49 c$ & $32.42 \pm 1.04 a$ & $7.11 \pm 0.99 c$ & $45.46 \pm 1.50 c$ \\
\hline $5 \% \mathrm{MA}$ & $1.52 \pm 0.10 c$ & $8.83 \pm 0.36 \mathrm{~d}$ & $23.05 \pm 1.65 b$ & $7.03 \pm 0.55 c$ & $59.58 \pm 2.34 a$ \\
\hline
\end{tabular}

${ }^{a}$ For each remediation treatment, mean values with different letters indicate statistically significant differences according to the LSD test $(P<0.05)$. EXC: exchangeable fraction, CA: carbonate fraction, $\mathrm{Fe}-\mathrm{Mn}$ : Fe-Mn oxide fraction, OM: organic matter, and RES: residual fraction. 
$5 \%$ MA for 60 days, the $\mathrm{pH}$ value of the soil samples increased from 5.46 to 7.20 and 6.83 , and the lead concentration extracted from TCLP decreased by about $52.6 \%$ and $95.2 \%$, respectively. And the concentration of lead bound to RES increased from $36.28 \%$ to $49.09 \%$ and $59.58 \%$, respectively. The incubation results show that both $\mathrm{BA}$ and $\mathrm{MA}$ can reduce the content of available lead in soil. However, MA shows less disturbance to the soil $\mathrm{pH}$, and it has higher immobilization efficiency and better immobilization stability to lead than BA. Therefore, MA is more significant than BA in reducing the environmental risk of lead and it has great potential as an amendment for soil contaminated by lead.

\section{Conflicts of interest}

The authors declare no competing financial interest.

\section{Acknowledgements}

This project was financially supported by the National Key Research \& Development Program (2018YFD0800300), the Project for Science and Technology Service of Chinese Academy of Sciences (CAS) (KFJ-SW-STS-172 \& KFJ-EW-STS-016), the Hundred Talent Program of CAS (2010-735), the aided program for Science and Technology Innovative Research Team of Ningbo Municipality (Grant No. 2014B82010 and 2015B11002), the Natural Science Foundation of Ningbo (2016A610266) and the Zhejiang Province Financial Support (LGF19D060001 and R5110230).

\section{References}

1 CDC, Low Level Lead Exposure Harms Children: A Renewed Call for Primary Prevention: Report of the Advisory Committee on Childhood Lead Poisoning Prevention of the Centers for Disease Control and Prevention, 2012, http://www.cdc.gov/ nceh/lead/ACCLPP/Final_Document_030712.pdf.

2 K. D. Bradham, C. M. Nelson, J. Kelly, A. Pomales, K. Scruton, T. Dignam, J. C. Misenheimer, K. Li, D. R. Obenour and D. J. Thomas, Environ. Sci. Technol., 2017, 51, 10005-10011.

3 H. Henry, M. F. Naujokas, C. Attanayake, N. T. Basta, Z. Q. Cheng, G. M. Hettiarachchi, M. Maddaloni, C. Schadt and K. G. Scheckel, Environ. Sci. Technol., 2015, 49, 89488958.

4 A. L. Juhasz, D. Gancarz, C. Herde, S. McClure, K. G. Scheckel and E. Smith, Environ. Sci. Technol., 2014, 48, 7002-7009.

5 X. D. Cao, L. N. Ma, Y. Liang, B. Gao and W. Harris, Environ. Sci. Technol., 2011, 45, 4884-4889.

6 H. B. Yin and J. C. Zhu, Chem. Eng. J., 2016, 285, 112-120.

7 L. Datko-Williams, A. Wilkie and J. Richmond-Bryant, Sci. Total Environ., 2014, 468, 854-863.

8 G. M. Filippelli and M. A. Laidlaw, Perspect. Biol. Med., 2010, 53, 31-45.
9 D. B. Smith, W. F. Cannon, L. G. Woodruff, F. Solano, J. E. Kilburn and D. L. Fey, Geochemical and Mineralogical Data for Soils of the Conterminous United States, USGS, Reston, VA, 2013, https://pubs.usgs.gov/ds/801/pdf/ ds801.pdf.

10 R. Pode, Renewable Sustainable Energy Rev., 2016, 53, 14681485.

11 S. Singh, L. C. Ram, R. E. Masto and S. K. Verma, Int. J. Coal Geol., 2011, 87, 112-120.

12 C. P. Liao, C. Z. Wu and Y. J. Yan, Fuel Process. Technol., 2007, 88, 149-156.

13 M. Narodoslawsky and I. Obernberger, J. Hazard. Mater., 1996, 50, 157-168.

14 M. Y. Zhao, Z. N. Han, C. D. Sheng and H. W. Wu, Energy Fuels, 2013, 27, 898-907.

15 L. Xu, H. B. Cui, X. B. Zheng, J. N. Liang, X. Y. Xing, L. G. Yao, Z. J. Chen and J. Zhou, Water Sci. Technol., 2018, 1, 115-125.

16 Z. L. Liu, D. Tian, J. G. Hu, F. Shen, L. L. Long, Y. Z. Zhang, G. Yang, Y. M. Zeng, J. Zhang, J. S. He, S. H. Deng and Y. D. Hu, Sci. Total Environ., 2018, 634, 760-768.

17 H. B. Cui, J. Zhou, Q. G. Zhao, Y. B. Si, J. D. Mao, G. D. Fang and J. N. Liang, J. Soils Sediments, 2013, 13, 742-752.

18 X. X. Ye, S. H. Kang, H. M. Wang, H. Y. Li, Y. X. Zhang, G. Z. Wang and H. J. Zhao, J. Hazard. Mater., 2015, 289, 210-218.

19 M. L. F. M. Kede, F. V. Correia, P. F. Conceicao, S. F. Salles, M. Marques, J. C. Moreira and D. V. Perez, Int. J. Environ. Res. Public Health, 2014, 11, 11528-11540.

20 U. S. EPA, Method 1311: Toxicity Characteristics Leaching Procedure, Test Methods for Evaluating Solid Waste, Physical/ Chemical Methods, SW-846, Office of Solid Waste, Washington D.C., 1996, https://www.epa.gov/sites/ production/files/2015-12/documents/1311.pdf.

21 A. Tessier, P. G. C. Campbell and M. Bisson, Anal. Chem., 1979, 51, 844-851.

22 B. M. Steenari and O. Lindqvist, Biomass Bioenergy, 1997, 13, 39-50.

23 X. D. Cao, L. Q. Ma, S. P. Singh and Q. X. Zhou, Environ. Pollut., 2008, 152, 184-192.

24 J. Boisson, A. Ruttens, M. Mench and J. Vangronsvel, Environ. Pollut., 1999, 104, 225-233.

25 Q. Y. Ma, T. J. Logan, S. J. Traina and J. A. Ryan, Environ. Sci. Technol., 1994, 28, 408-418.

26 A. Ito, K. Maekawa, S. Tsutsumi, F. Ikazaki and T. Tateishi, J. Biomed. Mater. Res., 1997, 36, 522-528.

27 R. Bade, S. Oh and W. S. Shin, Ecotoxicol. Environ. Saf., 2012, 80, 299-307.

28 Q. Y. Ma, S. J. Traina, T. J. Logan and J. A. Ryan, Environ. Sci. Technol., 1994, 28, 1219-1228.

29 E. Mavropoulos, A. M. Rossi and A. M. Costa, Environ. Sci. Technol., 2002, 36, 1625-1629.

30 Y. P. Xu, F. W. Schwartz and S. J. Traina, Environ. Sci. Technol., 1994, 28, 1472-1480. 